\title{
A Placebo-controlled Study of Repeated Subcutaneous Doses of COR-005 Alone or With Octreotide on GHRH-stimulated GH and Pharmacokinetics in Healthy Male Subjects
}

Klaus Kutz, ${ }^{1, *}$ Manuel Haschke, ${ }^{2}$ Christoph Beglinger, ${ }^{2}$ Jiri Liska, ${ }^{3}$ Carsten Dehning, ${ }^{4}$ Fredric Cohen ${ }^{5}$ 'AccelPharm, Basel, Switzerland; ${ }^{2}$ University Hospital Basel, Basel, Switzerland; ${ }^{3}$ CEPHA sro, Plzen̆, Czech Republic; ${ }^{4}$ Aspireo Pharmaceuticals Ltd., Tel Aviv, Israel; ${ }^{5}$ Strongbridge Biopharma, Trevose, PA, USA.
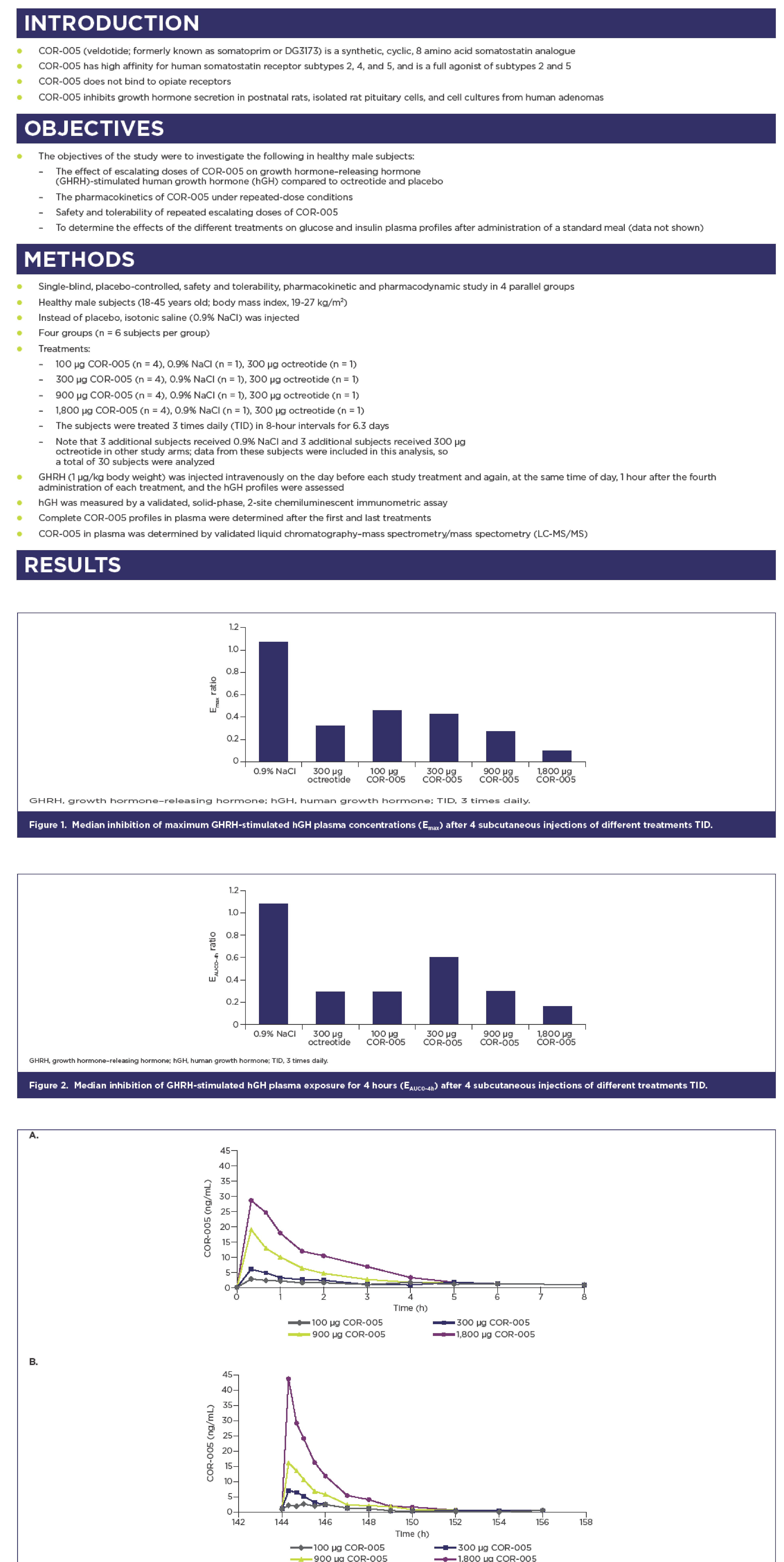

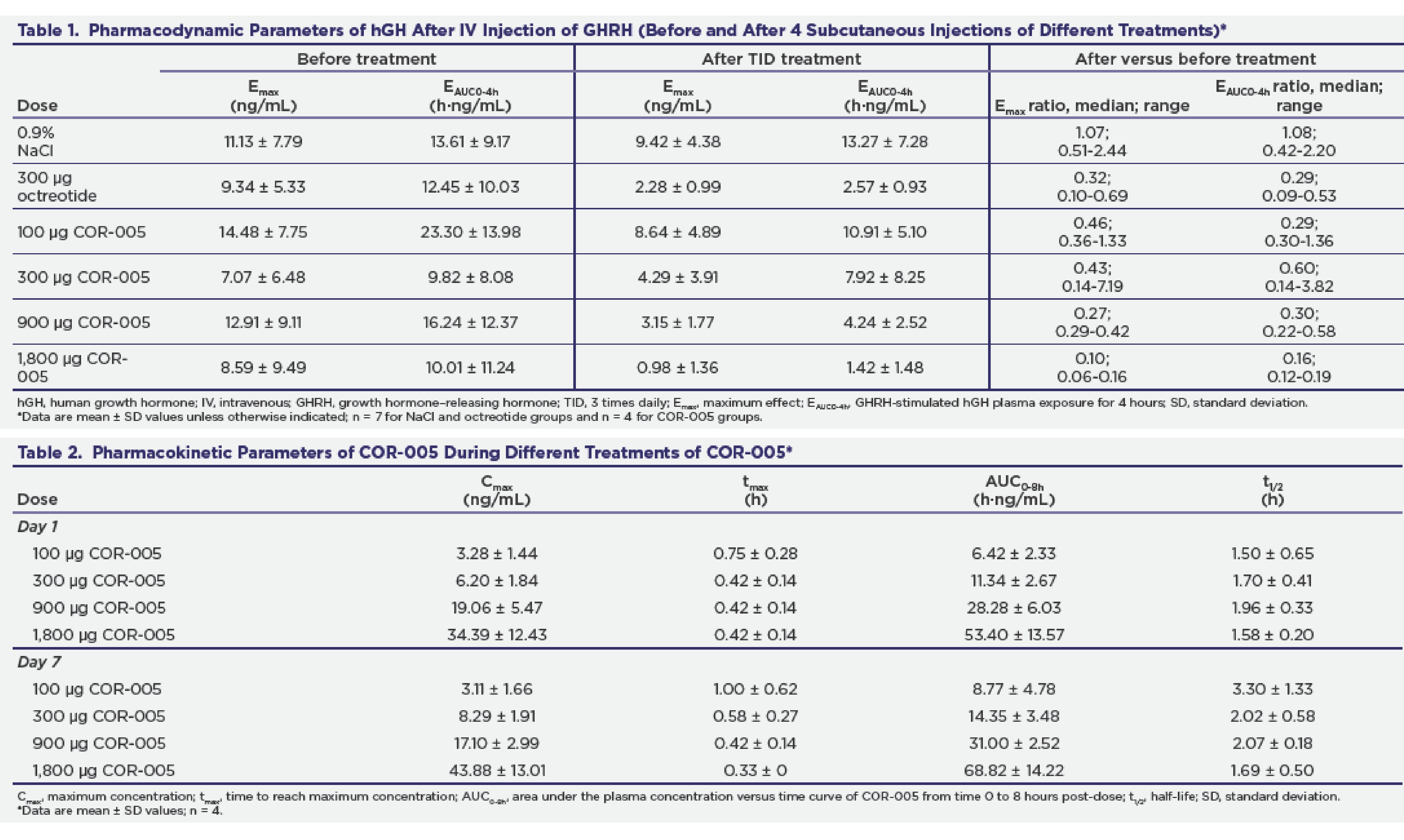

\section{SAFETY AND TOLERABILITY}

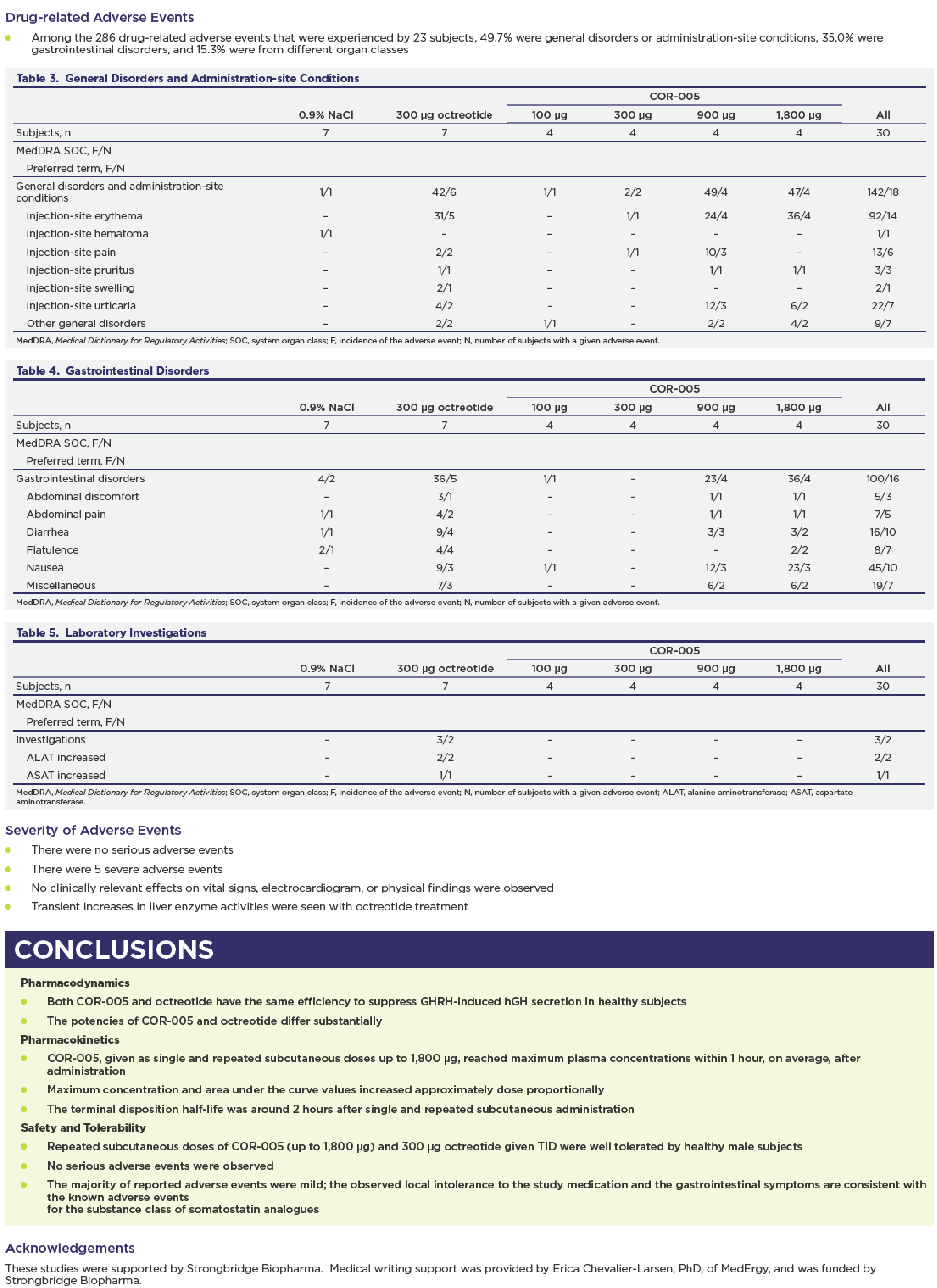

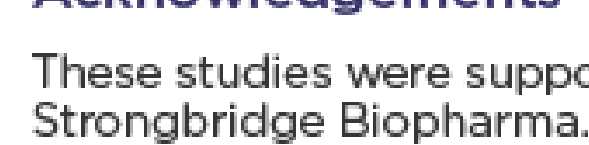

POSTER PRESENTED AT THE 18TH EUROPEAN CONGRESS OF ENDOCRINOLOGY (ECE); 28-31 MAY 2016; MUNICH, GERMANY. STRONGBRIDGE 